\title{
Soundtracks of Acrobatic Selves: Fan-Site Religion in the Reception and Use of the Music of U2
}

\author{
CLIVE MARSH \& VAUGHAN S. ROBERTS
}

\begin{abstract}
This article addresses the question of how responses to the arts and popular culture, as mediated through on-line fan activity, may contribute to the development of religious/spiritual exploration in contemporary Western societies. It offers a critical reading of 40 short essays posted by fans of the rock band U2 on a fan site from the perspective of how respondents expose their personal, critical reflections on their developing selves. The function of the U2 songs reflected upon, the listeners' responses, the strategies/processes used, and the resources upon which they draw in the task of reflection are noted and examined. The article maps a multi-disciplinary programme for examining responses, uses one sociological framework (as provided by the work of Margaret Archer) as a case study of how this multi-disciplinary framework may prove fruitful, and concludes by noting the benefits for contemporary religious/theological understanding of the on-line activity studied.
\end{abstract}

\section{Introduction}

It is widely accepted that people's interactions with popular music contribute to the development of their self-understanding and identities. Whether or not explicit, conscious or actively encouraged by the music listener, the combination of anecdotal and increasingly available research evidence indicates that a link often exists between the music a person consumes and both their selfperception and their self-presentation. It is part of the way in which consumption of popular culture and consumer choice work (Longhurst 123-4, 233-5; Negus 99-135; Cobb 184-8; North and Hargreaves 219-23). More detailed work is, however, needed to explore and explain how this happens, what 'self-understanding' or 'identity' means, and what else surrounds the practice of interacting with music, as a person expresses or becomes who they are. An early key text in this field is Erving Goffman's The Presentation of Self in Everyday Life. More recently, Charles Taylor has explored the development of 'self' in contemporary society through the contrast between the "porous self" in pre-modern thought and the "buffered self" of the modern world (Taylor 37-41, 300-07). Relevant also is David Sims's discussion of the "distributed self".

In this article we offer one limited contemporary study of the way in which the practice of the consumption of a rock-band's music provides evidence of how themes, experiences, and concerns, which are found in the discourses of religion and spirituality, are worked through on-line with respect to the self's development. Although there are many studies of U2, some of which explore the band's religious significance, and at least one which explores the importance of fandom as a phenomenon (Dorner), we have to date found only one devoted to fan-site reception (Lizie). While a useful and stimulating study, its interests are more to do with media and communications than religion/spirituality. Our concern is to examine the aspects of fans' self-presentation which go beyond the inter-personal, with respect to self-understanding, identity, and finding/creating value and meaning.

The interaction of U2 fans with the band's music indicates what is currently occurring in the field of popular music reception. Given U2's own origins and continuing engagement with religious themes and given the evident religious and spiritual interests of at least some U2 enthusiasts, this means that scrutiny of the reception of U2's music by fans also becomes an examination of a location within contemporary Western, even global, culture, in which religious exploration and meaning-making occur. 
We acknowledge that the term 'meaning-making' is fraught with difficulty. Cultural studies critics of the field of 'religion and popular culture' suggest that the meaning of meaning-making is often theologically loaded when religiously interested scholars do their work. While this is sometimes true, a term has to be found to describe a practice which recognizes that some kind of 'sense-making' occurs in the way people use the arts and media. We are trying to find a term which describes what people actually acknowledge they are doing with their music-listening habits and practices, which indicates at least an element of 'sense-making', 'shaping', 'structuring' of life or a process of clarifying commitments (Weick).

Our task was straightforward in conception. We critically examined a number of essay-length contributions to the www.atu2.com web site in the section headed 'Like a Song', in which those from the team of people who monitor the site ('staff') reflect on the significance of particular U2 songs for them. We obtained from Matt McGee, founder and webmaster of the site, information about the selection procedures of the 'staff' who write regularly for the site: no religious tests are applied. The religious and philosophical backgrounds of writers are not known (McGee).

By November 2010, the archive contained 50 essays, but the main research for this article was conducted in the late Summer and Autumn of $\mathbf{2 0 0 9}$ when we were able to scrutinize the contents of the first 40 . The numbers used hereafter in square brackets refer to the numbers of the essays, posted from 4.3.07 [1] to 18.10.09 [40]. We looked for explicit references to religion and spirituality and sought to assess how these were used. We also examined other elements within the responses, which indicated patterns, habits or styles of use of the music. Our method is thus textual analysis. Yet it is not analysis of lyrics alone. Rather, we examined reports of, and reflections upon, responses to and uses of music, both in recorded form and live performance. We focused on lyrics only as they were presented. It is not our purpose to dispute interpretations or use of songs selected with recourse, say, to authorial intention, or through reference to explicit, published, critically acclaimed interpretations of songs. As an exercise in music reception and use, we examined what U2 fans are actually doing with music.

The central motifs driving our study are contained in our title: 'soundtracks' and 'acrobat'. 'Soundtrack' may be an over-used metaphor for how popular music functions for many Western citizens, yet is no less significant for that: many clearly find it a helpful image for the way in which music accompanies people in life, expresses or interprets what happens to them, and helps them both to manage moods and undertake reflective work. Some of the contributors to the web site we studied confirmed this. 'Acrobat' is an image provided by U2. "Acrobat" is the penultimate song on the 1991 album Achtung Baby and is unique in being the only track from that album never to have been played live. The band did, however, return to the metaphor of the acrobat in later performances, for example, in an improvised lyric, "Ready for the Acrobat?", in "Zoo Station" on the opening night of the Vertigo Tour in San Diego in 2005. Lyrically the song reflects diverse themes in Achtung Baby: disillusionment with love ("One"), crisis over identity ("The Fly"), Last Supper ("Until the End of the World"). Bono has been quoted as saying: "Acrobat ... [is] a song about your own spleen, your own hypocrisy, your own ability to change shape and take on the colours of whatever environment you're in, like a chameleon." (Bono et al. 283). In his analysis of "Acrobat", Stephen Catanzarite (80) describes the song's central character as "an archetype of the conflicted self".

After an exposition and analysis of the material studied, we locate the patterns of use which are evident within a multi-disciplinary framework. We explore the acrobatic work undertaken by U2 fans in their dialogue with each other through the web site, given their apparent conviction that U2's music has provided a soundtrack within which they live and with which they can work in the discovery/construction of their selves. 


\section{U2 Fans in their own words}

We begin with findings from the 40 essays. Firstly, who are we dealing with? Only six of the 40 define themselves as being or having been explicitly religious. Few, though, are very specific. One speaks of having been brought up Catholic and now being Baptist [12]. Others are more general ("Given my faith..."; "I'm the praying type"). At least seven further contributors, however, offer expressions of what may be called spiritual searching or exploration in spirituality or meaningmaking, due to the manner in which they describe what they are doing with U2's music. Two refer to looking to fill that god-shaped hole in their lives-a citation from a U2 song entitled "Mofo" $[1,26]$. One speaks of aspiring to be "the deepest, brightest, most passionate self" she could be [2], another of the way a song prompts a glimpse "of what our very best selves could be" [37]. A third speaks of participating not in "some kind of worship, but the electric connection of shared humanity" when experiencing U2's music live [15]. Another contributor found that the song "In a Little While" became "more like a mantra than just another U2 song [she] loved". Three other essays refer to songs being like a 'mantra' [16, 38, 39].

In order not to focus simply on the already religious among U2 fans, or even the spiritual searchers, but to explore the point of intersection between habits of music use and 'meaning-making', we must look, secondly, at indicators of how keen U2 fans are to use the music in ways which may not necessarily be religious (explicit or implicit) and yet point to evident ways in which music shapes lives. A number of significant themes emerge.

First, contributors report on how the music, and their use of it, relate to their life practices. Five indicate how they use the music to relate to their life-experience [4, 6, 22], moods [15] or memories $[11,17]$. Two see significance in the fact that the music has accompanied their different life-stages $[2,21]$ and that the similarity in age of band-members (and thus the life issues they face and make music about) proves important [2]. Two others speak of the music as 'medicine' $[9,10]$. There are also references to confidence-building [13] and to the music accompanying running [1].

Secondly, there are different takes on what it is about the music that is significant. Three home in on the importance of lyrics, sometimes in isolation from wider considerations [6, 27, 34], while others emphasise the extent to which enjoyment and interaction with U2's music is about so much more than lyrics. One speaks of the music relating to "one's inner state of mind" and reflects on the "emotional architecture" of the music [18]. Another talks of having to "live" the music in order to understand it [8]. There is much reference to the emotional impact of music [3: "primal feeling"; 15; 29: "You can't listen to U2's music and not feel"]. In addition, reference is made to songs that can "really lift the soul" [27; cf. 38: "really lifted me up"]. Others note the particular impact of live performance over recorded versions of U2's music $[3,15]$.

In addition to these pointers about linking with life and the multiple ways in which songs have proved meaningful, there is also, thirdly, a layer of comment on how or why U2's music 'works'. Five people refer to the time it takes for a particular song to 'work'. Here, there is sometimes an assumption that there is a 'right' meaning, an authorial meaning, or a definitive interpretation, of a song which has to be 'got', which the listener feels $s /$ he finally stumbled upon at some point in his/her life [6]. Yet often it seems more a case of 'not liking' and moving to 'appreciating'/'enjoying'/'using' as a result of being at a different life-stage or able to draw on a specific life experience in interacting with a song $[9,10,29]$. At least three refer to the fact that songs may have multiple meanings or be open to multiple legitimate interpretations, even in the experience of a single listener [5, 26, 28]: 
... [T]hat's the beautiful thing about great music: It has different meanings for different people... [5]

One day a song can just be a cool tune that rocks. And then on another day the same song can actually make the past, the present, or even the future so much more in focus than it ever was before. This is one of the great things about music, isn't it? [26]

One writer narrates the shift in meaning produced by hearing "Where the Streets have no Name" played in a church prior to a memorial service [17].

Fourthly, more proverbially, there are many references to U2's music being a soundtrack for people, either of their own lives, their "personal music history" [21], "for transformation" [1] or "of the city" [2]. In referring to her chosen song as the soundtrack for her "journey of the spirit", a further writer presents the significance of a U2 track at its sharpest: "I still haven't Found What I'm Looking for" "has shaped and influenced who I am" [28].

Between the lines of those four general observations about what people explicitly present, there is more material to be uncovered which is pertinent to our enquiry. At this next level of analysis, note is taken of elements in the interpretations offered which seem to cry out for closer attention than the essay writers themselves provide. We note four such elements.

First, we observe a willingness on the part of a number of writers to speak of their "obsession" with U2 or with the particular song they are interpreting $[3,6,7,22,28,40]$. When uttered by fans, this is clearly not offered as a negative reading of the intensity with which speakers refer to their engagement with U2 and their music. As one such 'obsessive' also suggests, it is about being "passionate ... dedicated ... committed" to U2, their music, and their causes [7]. We are, however, dealing here with the borderline between passionate engagement and obsession. The kinds of people who write the on-line essays we have been studying, contribute blog comments, and check fan-sites daily reveal a level of commitment to following U2 which indicates that at the very least much leisure time is spent in dialogue with $\mathrm{U} 2$ and other U2 fans. The extent to which, and the way in which, such intense practice itself is 'person-shaping' and how this is to be understood deserves multi-disciplinary enquiry.

Secondly, we note the degree of self-exposure which occurs in the essays. They contain accounts of: handling the death of loved ones (a child [36]), a struggle with anorexia [29], dealing with an accident, battling cancer [22], coping with disability and failed relationships. There are also attempts to speak of utter joy [15], transcendence, recognizing and confronting the "universal nature of human suffering" [6]. It is striking how much of life becomes evident in the space of 40 short, personal essays, which respond to songs written over the past four decades. Many of life's extreme challenges are here. In one of the later essays [36], it is clear that, unlike in many explicitly religious settings where it may be felt that 'meaning' or 'sense' has to be found, the web site gives space not to be under pressure to 'make sense' (here, of the death of a child) or simply to 'accept', but nevertheless to acknowledge openly what has happened and to record one's response to the occurrence via action. Admittedly, in psychological or pastoral theological perspective, more questions might be asked about the nature of the writer's response, but such questions lie beyond the scope of this article.

Thirdly, there is an intriguing thread running through some of the essays about how Bono's voice, or Bono himself, is spoken about. Here are four examples: "Bono was there to help me get back on my feet" [9], "Bono's voice became my medicine" [10], "it seems as though Bono is speaking directly 
into my ear" [18], "U2 and particularly Bono had changed my life, in some ways saved it" [40]. In these, and at other points in the essays-even if fans might dispute that they are divinising Bono ("Bono is not God" [40]) - the manner in which Bono is referred to can sound like references to God. It could easily have been God who got a person back on their feet or spoke into their ear or whose voice worked like medicine. The actual use of music and the metaphorical aspect of religious language meet, so that language describes what happens to the listener. Something, be it reassurance, healing or well-being, is mediated by the music at the point of its reception.

Fourthly, religious ideas and beliefs occasionally surface in potentially problematic ways. For example, beliefs can be drawn from a range of religious traditions without much thought as to the implications of juxtaposing them. "Karmic sins" [22] are as readily referred to as the crucifixion of Jesus or the gift of the Holy Spirit [33]. A "guardian angel" is spoken of [33] and theological convictions are expressed which, while sounding commonplace or straightforward, are less orthodox or credible than they seem ("if one lives an ethical and mature life of rectitude and truth, light and fulfilment will always be shining on us" [25]).

Of course, the references come from different people, with radically different life experiences from each other, but the result is that meaning-making is seen as an individualistic enterprise. Religious ideas and beliefs, as relating to religious communities, have little claim on the currency of the language use. This point suggests at the very least a potential clash of community discourses: between the U2 community of which respondents are a part and the religious communities on whose traditions they sometimes depend in their responses.

There is, then, a wide range of material, some explicitly religious, much not, which invites both exploration and explanation, given the way in which $\mathrm{U} 2$ fans report and reflect on their uses of the band's music. However, what is to be made of this in more analytical terms when we draw on the insights of varying academic disciplines?

\section{Frameworks for Understanding Fan Responses}

Critical analysis of what is going on at the point of such music reception needs to place the material within a multi-disciplinary framework. The lenses through which we are most competent to read such material (theological-religious, allowing for the fact that theological and religious readings are always to some extent inter-disciplinary) would be a legitimate, although also a limited, reading. It would need to feature in order to gain the fullest possible picture of the process of reception and use. In moving beyond our own comfort zones, however, we have ventured into distant and farranging territory. We have needed to draw on: (i) sociology, both in relation to the study of reflexivity (Archer) and the habits of daily music usage (DeNora); (ii) social psychology and the functions of music in daily life (North and Hargreaves); (iii) popular music and cultural studies (Longhurst; Middleton; Negus; Frith; Lynch); (iv) media studies and the phenomenon of fandom (Hills; Gray); (v) musicology, particularly with respect to the affective dimension of music reception (Juslin and Sloboda), (vi) anthropology, in so far as it influences liturgical studies (Bradshaw and Melloh; Davies).

A full theological-religious analysis of the material we have examined would need to draw on all of these areas. The scope of such a study would be considerable and yet a comprehensive theologicalreligious assessment would be premature without it. There is only space in this article to illustrate how one of these disciplinary readings might develop and be made use of in relation to an understanding of this case study of music response in religious terms. We have chosen to use the sociological approach as a case study of what is possible and fruitful. We use the sociological work of Margaret Archer as a framework within which to map the fan use of U2's music.

In her research into the 'private life' of the human mind, Archer has identified three forms of "inner conversation" which she calls: (i) communicative reflexivity, (ii) autonomous reflexivity, (iii) meta- 
reflexivity. Communicative reflexivity is characterised as a form of mental deliberation which depends upon conversing with similar others, such as close family or longstanding friends. In this process the private thoughts of the mind are confirmed by exposure to those we trust, which Archer calls "thought and talk". She argues that people who have this form of inner conversation

are people who do indeed initiate internal dialogues in the privacy of their own minds, but that is not where they complete them. Instead, their pattern is one of 'thought and talk'. Having raised an issue intra-personally, they seek to resolve it inter-personally. They share their problems, discuss decisions and thus externalise much of what, to other interviewees, remains intrinsically an internal deliberative process. (Archer, Making 167)

This form of reflexivity requires a group with whom a reflexive agent can interact. It also acknowledges that engagement of this type requires "completion and confirmation by others before resulting in courses of action" (ibid 93). As noted, close family members and longstanding friends tend to form the necessary group for this type of reflexivity.

As evident in the texts we studied, U2 fans easily find other aficionados to share 'thought and talk' through the internet. This is also present in some of the personal essays on the atU2 web site. For example, the person who wrote about the song "Breathe" [35] observes how external factors such as close family and community membership contribute to the process of identity formation:

We all have someone or something we love so much that it defines us. We all have things that make us who we are. When you're frightened, when it feels too hard, that's when you need your clear brain and your strength the most-so run, run to the things that make you breathe. Whether you find them in art, family, religion, helping others, reading books, gardening, hiking, counting stars, no matter ... stand in the space of those things and breathe the pure oxygen they give you.

By contrast, autonomous reflexivity is a lone exercise whereby the private life of the mind is an internal dialogue not supplemented by external exchanges with other people. It is an individual process of 'mulling over' problems or 'sussing out' solutions which, Archer believes, shows a degree of self-confidence in one's own ideas. One of Archer's interviewees spoke about how he used music in this reflexive activity (Structure 223):

He does his 'mulling over' or 'sussing out' when listening to music. 'That always helps when I'm trying to think about something-or lying down listening to music, that's good. When you think about something, it clears your head-it's much better than sitting up. And I have to be on my own as well, to think about something. Because you've always got someone speaking to you, and you, like, can't think about it properly if you've got to answer their questions and things like that.'

Again, there are examples in the 'Like a Song' section on the atU2 web site, which show individuals using tracks to work through particular issues at a personal level. The commentator on "A Room at the Heartbreak Hotel" deals with an experience of unrequited love [18]:

I tried to exorcise the pain as much as possible through writing songs and poems, but I felt empty, devoid of any creative drive. The block restricting my writer's impulse had turned into a boulder, and I was constantly hampered by the awareness that what I was feeling was not the centre of the universe, 
unworthy of the serious study I was trying to ascribe to it... That was, until one miserable evening when I plugged into my iPod and played a song 'A Room at the Heartbreak Hotel'.

Archer's third category is meta-reflexivity which is a working of the inner mind characteristic of idealists (Structure 258):

These are people with a vocation (or in search of one) in which they can invest themselves and which is expressive of their ideal. As idealists, they experience a constant tension between structure and culture. No existing social arrangements approximate to their ideal, nor ultimately does any institution or organisation to which they are vocationally drawn.

Archer draws on Max Weber's Science as a Vocation when she states (ibid 267) that "A vocational commitment entails a subjective investment of the self and a voluntary quest for selftransformation, such that one comes closer to personifying the ideal qualities which ideally express it". Those who engage in this form of reflexivity need: (a) a social setting which conforms to their ideals, (b) a small group of colleagues who share the same vision, (c) an environment conducive to their physical and mental well-being (ibid 278). Archer's notion shares common ground with what Adrian North and David Hargreaves, and many others, call "communities of practice" (320).

In the discussion of the song "MLK" [16], the writer considers Martin Luther King's 'I have a dream' speech and then makes a statement that exhibits much of the characteristic idealism of this form of reflexivity:

Like ancient cultures and Dr. King, who both used dreams to shape their world, I also have dreams. Like all of these people, my dreams concern myself, my loved ones and the greater good-at least as I see it. Some dreams seem to be at odds with each other and create an inner struggle. I dream of becoming less materialistic while another dream is that those closest to me have everything they need. I dream of strengthening the areas of myself that I find lacking while also dreaming of not becoming a self-absorbed person. I dream of a world where justice and equality create an atmosphere of respect for all while struggling not to be drawn in to the corporate world where self-promotion is required to move ahead. Finding the proper balance is very difficult.

It can be argued that alongside the commercial aspect of what is undoubtedly a large and successful business, the U2 enterprise and the individuals who are driving it are shaped by the formative culture which Archer identified - the need for a social setting which conforms to their ideals, a small group of colleagues who share the same vision, and an environment conducive to their physical and mental well-being. A tension is undoubtedly created and the ambiguous relationship between ideals and organisations is reflected in attributed quotations. Bono is widely reported as saying

Even though I'm a believer, I still find it really hard to be around other believers: They make me nervous, they make me twitch. I sorta watch my back. Except when I'm with the black church. (Bono)

This type of reflexivity is reflected in many U2 lyrics, including the song "Acrobat" where Bono sings of the difficulty of finding a 'movement' or a 'church' to believe in and belong to. 
The fact that the U2 enterprise grew from, but cannot be contained within, and sits uneasily in relation to, any ecclesiastical structure reflects the tension between meta-reflexivity and communicative reflexivity. Although all need formative and authoritative communities and traditions to which to relate, these do not always represent the ideals for which people seek. Nor do they necessarily allow people the scope to interrogate and explore the values and beliefs implicit in the communities which formed them. Archer's conceptual framework for understanding internal conversations allows for this, too. She speaks of "fractured" reflexivity: when there is not just tension but conflict in different forms of reflexivity in a person's internal conversations (Making 93, 96). In functioning as a community of friends (to support communicative reflexivity) and as a space within which meta-reflexivity becomes possible, the U2 fan community can serve both purposes for individual fans. It must, however, function less normatively than a religious community, even while the band displays overt ethical and political commitments and the fan communities indicate that many U2 followers are principled, politically active citizens.

\section{Assessing the Role and Functions of the U2 Fan Community}

The on-line U2 fan community brings into the same space enthusiasts for U2's music who often also seek to clarify their ethical commitments and a community of practice to which they can relate in shaping their identities and philosophies of life. Using Archer's terms, U2 fans' 'meta-reflexive' negotiations may sometimes be indistinguishable from forms of 'communicative reflexivity' in so far as other fans are seen as close friends. However, it is also clear that not all U2 fans share identical beliefs. One of the discussion strings on the atu2.com web site bemoans the volume of theological discussion on the fan site.

U2 fan sites can, however, function meta-reflexively precisely because they provide a space beyond clearly demarcated religion-specific spaces where those of faith or no faith can work out critically their life-commitments on the basis of, and in dialogue with, their own and others' experience of and response to U2's music. The lack of specificity creates the freedom to explore. Yet it also raises the question of what traditions or traditions of thought and practice are drawn upon in order to support the commitments which are continuous with what U2 as a band seeks to promote. Is this, in short, a new religion, an inter-faith movement or a modified, contemporary form of Christianity or none of these? Also, does it matter?

As indicated, a detailed exploration of these questions can only be multi-disciplinary and would take us well beyond the present article. We have taken only the first steps here. There are many other ways in which such fan material could be analysed. Such analysis would not necessarily deliver what theologians, religious practitioners or even religion scholars hope it might. We simply do not know where the enquiry would lead. However, if scholars from different ideological, faith, and disciplinary commitments fail to sit round the same table in the task of analysis, they (we) shall not collectively get to grips with how the reception of music functions and what it achieves, in the contemporary West. Being able to show that reception and use of music provoke the deepest of internal conversations, foster person-to-person exchanges, and create virtual communities in relation to which diverse forms of reflexivity occur should at least alert us to its importance. It may be too simple to call popular music today's liturgy, although lyrics are sung, memorised, used, lived within, and frequently function in the way authoritative scripture functions in liturgical worship. As Don and Emily Saliers (40-1) note with respect to repeated listening to music and ritual:

Why do so many people keep going back to certain songs again and again? For both of us, it is a matter of searching for moments of insight, for the secrets in the words and music that have moved us, or for a sense of the illumination they once provided, like patches of light across our pathways. In returning to a song, we hope to find that light again, and we hope that it will lead us again to a little 
clearing in a dense forest. Just as people repeat rituals, we want to return again and again to certain music.

The evidence of the way $\mathrm{U} 2$ fans use the band's music clearly suggests that such use of music creates at the very least a virtual community of enquirers in which religious exploration is explicit, acceptable, and sometimes religion-specific, while not necessarily functioning normatively for those participating in the conversation. Public discussion not simply of religion, but of the subject matter which religions address, is thus brought to a new place, a context where the affective, aesthetic, cognitive, and ethical meet, beyond the immediate reach of religious orthodoxies and channels of religious authority.

As well as needing to draw extensively on the other disciplines identified earlier, further enquiry would also benefit from more empirical data derived from analysis of web-site contributions. We suspect there is more work to be done with Archer's categories and perhaps, as a result of using them, more work with testing the categories themselves. However, this would involve the study of the discussion strings within fan sites, on more than one fan site, and (potentially) qualitative data based on semi-structured interviews with a selection of U2 fans would be important.

For the moment, we conclude with observations on the material gathered and discussed in the previous two sections. Our contention is that the de facto function of U2's music at the point of reception carries consequences not just for understanding how fandom works, but also for what may be happening to 'spirituality' in the widest sense. We wish to note that it has theological consequences, in that the meaning and adequacy of the concepts which people work with in their personal reflections are tested in a public space. Theologians/thinkers within varying theological traditions - the Abrahamic faiths and arguably Christianity in particular, given U2's roots-may need to pay heed to such uses.

We must understand the fan site as an 'affective space'. We are not following the technical use of the phrase by psychologists to denote facial reactions to visual images. We mean, rather, that emotions are always in play in the process of the reception and use of media and works of art and that a viewer/listener therefore 'plays with' what $s /$ he does with the music, film, TV programme, work of art s/he engages with. 'Affective space' is thus a location, a context, in which emotions are experienced and explored. The space is not neutral, but it is recognized that meaning and use are not determined by either the product (work of art) or the consumer (listener/watcher) alone (Marsh).

In post-Christendom times, it is inevitable that people are less constrained by, or focused upon, the specific resources of a particular tradition alone. Yet to be human, human beings undertake cognitive work in relation to what moves them. This can no longer be, if it ever was, processing experiences in relation to 'religious affections' alone. Theology still has to do its work, as one discipline among many and as a discipline which understands that questions about authoritative narratives inevitably arise for the necessary evaluative work to be done, where human affections are exposed and used in the task of constructing identities and meanings.

We say 'evaluative work'. This is simply a way of recognizing that decisions have to be made about what it is worth spending time on (in terms of practices to be engaged in) and how one then assesses what beliefs to hold, ideas to have, and ethical stances to assume. Authority also comes into play (whom do I trust?), as do institutions (whom do I ally myself with?) and commitments (am I going to give any time to this or that?). Theology may be more interested than some disciplines in questions of authority. Yet it is not the only discipline to know that if 'anything goes', with no critical, evaluative work undertaken, people may well end up 'believing anything'. For the purposes of this 
article and this journal, however, it is important to step back from the evaluative (theologically normative) stage, while recognizing the theological significance of our findings.

U2 fan-site activity reveals that users are disclosing and working with their affections and that they are sometimes evidently religious, sometimes not. Response to U2's music is the playful and acrobatic activity which becomes the highly productive affective space within which such cognitive work is undertaken. The U2 material is, however, more diffuse than what theologians normally work with, because it is less directly identifiable as 'religious experience' or as related to a religious community. Therefore, the theological task is different. Archer's sociological framework is helpful to see what is going on. A theological study of this material would have to go further. We finish, however, by walking the tightrope between sociological observation and the beginnings of theological questioning. Our hope is that we demonstrate where important, evaluative questions emerge at the interface between disciplines.

We return to the four observations drawn from what opened up within the affective space created by U2's music (obsession, self-exposure, Bono, beliefs). It was noted, first, that a number of respondents do not find it problematic to speak of their following of U2 as an obsession. This is perhaps because they do not think of it as an addiction. Self-ownership of the term 'obsession', however, acknowledges the intensity of one's commitment. Religion could be said to be caught between feeding addiction at the one extreme (more and more of the same) and thirst for constant novelty at the other (never repeat anything and resist all norms). Healthy religious practice knows that in cultivating habits of piety it seeks to enable people to structure life meaningfully. (By 'piety' we mean simply the disciplined practices which religions promote.) This observation could be seen as arguing religion away, via explanation, sociologically or psychologically. More accurately, it is a way of saying that this is how things often work for those who believe in God. 'Belief in God' means acknowledging the presence of God and linking such awareness with religious practices (habits of piety) which acknowledge that presence, whether that happens to be reading the Bible or accessing a U2 fan site. In this light, these are not simply similar practices. They become the shared affective space within which what some define as divine reality is explored through the intensity of engagement in human experience. Some U2 fans (whether affiliated to a religious group or not) undertake this explicitly. Some resist such interpretations. Yet the 'Like a Song' section of the fan site we have studied is a shared space in which similar experiences are explored and reflected upon. It is also the intensity of fans' commitment to the band, and the regularity with which they access the fan site, that makes this disciplined practice religion-like. The disciplined/obsessive degree of practice recognizes the level of commitment required to address the different forms of reflexivity necessary to work towards personal fulfilment.

The level of self-exposure takes this a stage further, disclosing the extent to which, and the way in which, people participate in their own identity-formation, and self-discovery or self-construction, by critically reflecting on their various responses to and use of U2's music. This is an active involvement to which those who study religion need to pay attention and which the forms of reflexivity identified help to map. Such self-exposure, in the service of self-construction, occurs explicitly in religious life. It may be happening less than supposed, however, and explicit forms of religion may be proving passive in comparison with people engaging with the arts and popular culture. As much media reception study shows, participants/receivers are always active in some way. The active, conscious practice of participation has perhaps led to the displacement of self-construction from religion to popular culture because of the perceived passivity of the former. Yet the forms of reflexivity identified here would need to be worked with by any theology which wants to take actual, lived human experience seriously.

What about the way people spoke about Bono? This can be read in a number of ways: as celebrity worship or idolisation. It could, however, be deemed iconographic. The term 'icon' is certainly over- 
used in Western culture, often meaning little more than 'very significant image'. Yet when an image has the function of a channel, a mediation, of divine presence, grace or activity, it may justifiably be called iconic. Some of the references to Bono's words or voice undoubtedly reflect a form of devotion. But mediation of something beyond the image is also being identified. An unhealthy obsession with Bono clearly develops among some U2 fans, an issue which is explored openly, with lingering ambiguity, by one of the essay writers studied [40]. Yet what people report is genuine reassurance, healing, well-being, mediated by a voice and a public persona rather than by a visual image alone.

Finally, there is the mixing together of beliefs from different religious traditions. This can prove problematic for some Christian theologians, because when dealing with responses one can appeal neither to the origins of U2 in Dublin evangelicalism, nor to band intentions at whatever stage of their collective life a song was written, in order to establish which beliefs should be held to function normatively. When listeners bring into their response a mixture of religious ideas and beliefs from many places and traditions, the range cannot be controlled. At issue is how this is to be turned into norms. Who has authority? From one angle, the answer is clear: the individual respondent has all the authority (and why should anyone need to worry about norms anyway?). Only if $s /$ he is trying to be a loyal (orthodox) Christian, Buddhist or Hindu does it become necessary to ask with respect to which authoritative sources or resources a process of reflection is to be evaluated. This is a testing matter for all religious traditions. Hinduism may cope with it better than most other faiths because of the extent of its inclusiveness. Other traditions may simply have to accept that as 'pick ' $n$ mix' spirituality increases and technology fosters increasingly global communication of ideas and beliefs, the only theology which can be practised must in part be comparative theology (as, for example, in the works of the Christian theologian Keith Ward). In terms of the different forms of reflexivity identified, it is clear that 'meta-reflexivity' need not be bound to a single religious tradition, even if it is in practice difficult to draw from many and remain easily coherent. Arguably, though, metareflexivity more readily describes the person frustrated with religious traditions which cannot work together in the service of humanity as a whole.

The 'acrobatic selves' which are constructed in the affective spaces opened up by U2's music are sometimes explicitly religious, but often not. At the point of fan discussion of the band's music, various forms of reflexivity, as identified by Archer, are clearly at work and offered to public view. Within such self-presentation, explicit religiosity and concerns and issues of interest to contemporary discussion of religion and spirituality do surface. Whatever understanding of 'the self' is worked with (be it buffered, distributed, ideal or some other form), for some U2 fans the process of responding to the band's music provides them with the tools, the context, and the incentive to 'think things through' in relation to what has moved them. The affective space may not always be seen as a sacred space, but it is where identity-formation occurs and where, at least for some, much else happens, too.

\section{REFERENCES}

Archer, Margaret. Being Human: The Problem of Agency. Cambridge: Cambridge UP, 2000.

- - - Structure, Agency and the Internal Conversation. Cambridge: Cambridge UP, 2003.

- - - Making Our Way through the World. Cambridge: Cambridge UP, 2007.

Bono. Rolling Stone Interview. 20 October 2005. Available at: http://u2_interviews.tripod.com/ id262.html, access date: 1 December 2010.

Bono, the Edge, Adam Clayton, and Larry Mullen Jr., with Neil McCormick. U2 by U2. London: HarperCollins, 2008.

Bradshaw, Paul, and John Melloh, eds. Foundations in Ritual Studies: A Reader for Students of Christian Worship. London: SPCK, 2007.

Catanzarite, Stephen. Achtung Baby. London: Continuum, 2007. 
Cobb, Kelton. The Blackwell Guide to Theology and Popular Culture. Oxford: Blackwell, 2005.

Davies, Douglas. Anthropology and Theology. London: Berg, 2002.

DeNora, Tia. Music in Everyday Life. Cambridge: Cambridge UP, 2000.

Dorner, Brigitte. U2 ist ihre Religion, Bono ihr Gott. Zur theologischen Relevanz der Rock- und Popmusik am Beispiel von U2. Marburg: Tectum-Verlag, 2007.

Frith, Simon. Performing Rites: On the Value of Popular Music. Cambridge, MA: Harvard UP, 1996.

Goffman, Erving. The Presentation of Self in Everyday Life. 1959. London: Penguin, 1990.

Gray, Jonathan, ed. Fandom: Identities and Communities in a Mediated World. New York: New York UP, 2007.

Hills, Matt. Fan Cultures. London: Routledge, 2002.

Juslin, Patrik, and John Sloboda, eds. Music and Emotion: Theory and Research. Oxford: Oxford UP, 2001.

Like a Song. www.atu2.com web site. Available at: http://www.atu2.com/news/?Key= likepapsong\&Scope=Headlines\&Year $=\&$ Cat $=12 \&$ Action $=$ Search $\& x=51 \& y=17$, access date: 1 December 2010.

Lizie, Arthur. Dreaming the World: U2 Fans, Online Community and Intercultural Communication. Cresskill, NJ: Hampton P, 2009.

Longhurst, Brian. Popular Music and Society. Cambridge: Polity P, 1995.

Lynch, Gordon. Understanding Theology and Popular Culture. Oxford: Blackwell, 2005.

McGee, Matt. E-mail to Clive Marsh. 28 April 2010.

Marsh, Clive. "Adventures in Affective Space: The Reconstruction of Piety in an Age of

Entertainment." Epworth Review 37.3 (2010): 6-20.

Middleton, Richard. Studying Popular Music. Milton Keynes: Open UP, 1990.

Negus, Keith. Popular Music in Theory: An Introduction. Cambridge: Polity P, 1996.

North, Adrian, and David Hargreaves. The Social and Applied Psychology of Music. Oxford: Oxford UP, 2008.

Saliers, Don, and Emily Saliers. A Song to Sing, a Life to Live: Reflections on Music as Spiritual Practice. San Francisco: Jossey-Bass, 2005.

Sims, David. "Living a Story and Storying a Life: A Narrative Understanding of the Distributed Self." Eds. Pullen Alison, and Linstead Stephen. Organization and Identity. London: Routledge, 2005. 86104.

Taylor, Charles. A Secular Age. Cambridge, MA: Harvard UP, 2007.

Ward, Keith. Religion and Revelation. Oxford: Clarendon P, 1994.

- - . Religion and Creation. Oxford: Clarendon P, 1996.

- - Religion and Human Nature. Oxford: Oxford UP, 1998.

- - -. Religion and Community. Oxford: Oxford UP, 2000.

Weick, Karl E. Sensemaking in Organizations. London: Sage, 1995. 